\title{
Numerical simulation of heat and mass transfer in a closed two - phase geothermal thermosyphon
}

\author{
Lily Valieva ${ }^{1, *}$, and Alexander $\mathrm{Nee}^{1}$ \\ ${ }^{1}$ National Research Tomsk Polytechnic University, 634050 Tomsk, Russia
}

\begin{abstract}
Mathematical model of the heat and mass transfer process in a two-phase thermosyphon with allowance for the coolant phase transformations is presented in this study. The formulated boundary-value problem was solved by the finite differences method. The numerical experiment results are presented and the temperature fields are obtained for different operation times of the geothermal thermosyphon.
\end{abstract}

\section{Introduction}

The unconventional energy sources are attracting increasing attention in the conditions of continuous growth of energy consumption and fossil fuels depletion [1-4]. The active solar radiation and wind use to generate electricity and heat is hampered by huge capital and operating costs. Moreover, such energy sources are not stable. Their power depends significantly on the climatic conditions of the terrain and time.

Geothermal energy has the greatest prospects [5]. U-shaped heat exchangers are used to extract energy [6]. However, the use of such heat transfer devices is accompanied by difficulties in mounting. Geothermal closed two-phase thermosyphon (GTS) can be an alternative substitute [7].

Only two studies have been published in the open press $[7,8]$ devoted to the operation analysis of closed two-phase thermosyphon under geothermal energy transfer conditions.

The various parameters influence on the characteristics of a geothermal thermosyphon was studied by Frank Hartmann et. al.[7] Heat and mass transfer two-dimensional numerical model was resolved and a physical experiment was carried out with different wetting coefficients, tube materials, radii and thermal conductivities of the head well.It is proved that the reduction in the well diameter leads to an increase in the heat flux. The well and soil thermal conductivity are important influencing parameters. The wetting effect, soil material and thermosyphon on the heat transfer coefficient are modeled based on the quasithree-dimensional thermal equation conductivity in [8]. It is proved that the wetting factor and the GTS body material affect to the heat fluxes transmitted. It is established that polyamide materials can serve as an alternative substitute for the steel body of the heat exchanger.

\footnotetext{
* Corresponding author: lil.Valiewa@yandex.ru
} 
It is assumed that heat in the system is transmitted only by conduction. Moreover, the issue of heat transfer in the direction of the vertical coordinate was not considered. It is very important in analyzing the geothermal thermosyphon efficiency. Therefore, the present work purpose of is mathematical modeling of heat and mass transfer in a closed two-phase geothermal thermosyphon.

\section{Mathematical model and numeral method}

The geometric problem formulation is shown in fig. 1. The vertically oriented TS consists of a sealed copper body (4) filled with working fluid (water). Heat is supplied to the thermosyphon bottom cover (1). The intensive evaporation process begins at the boundary (5). Because of forced convection, the vapor moves to the top cover (3). It condenses on the surface (6). The condensate formed due to gravity flows downward. The heat is removed from the top boundary (3) according to the Newton-Richmann law.

It was assumed that the thermophysical characteristics of the refrigerant and the body are temperature independent [9].

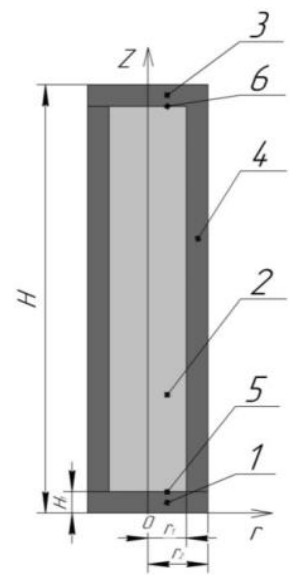

Fig. 1. Solution domain: 1 - bottom cover; 2 - vapor channel; 3 - top cover; 4 - enclosures; 5 evaporation section; 6 - condensing section.

The heat and mass transfer process in a two-phase thermosyphon is described by the following equations:

- Thermal conductivity equation for the enclosures:

$$
c_{1} \rho_{1} \frac{\partial T_{1}}{\partial t}=\lambda_{1}\left(\frac{1}{r} \frac{\partial}{\partial r}\left(r \frac{\partial T_{1}}{\partial r}\right)+\frac{\partial^{2} T_{1}}{\partial z^{2}}\right)
$$

- Thermal conductivity equation for the vapor channel:

$$
c_{2} \rho_{2}\left(\frac{\partial T_{2}}{\partial t}+W \frac{\partial T_{2}}{\partial z}\right)=\lambda_{2}\left(\frac{1}{r} \frac{\partial}{\partial r}\left(r \frac{\partial T_{2}}{\partial r}\right)+\frac{\partial^{2} T_{2}}{\partial z^{2}}\right)
$$

where $W=\frac{W e v}{\rho} ; \rho$ - density, $\mathrm{kg} / \mathrm{m}^{3} ; W_{e v / c o}-$ specific mass evaporation/condensation rate, $\mathrm{kg} /\left(m^{2} \times s\right)$. 
Rate of evaporation/ condensation is calculated according to the formula HertzKnudsen [1]:

$$
W_{e v / c o}=\frac{A\left(P_{n}-P^{*}\right)}{\sqrt{\frac{2 \cdot \pi \cdot R \cdot T}{M}}}
$$

where $A$ - accommodation coefficient; $P_{n}$ - saturation pressure, Pa; $P^{*}$ - partial pressure, $\mathrm{Pa} ; R$ - universal gas constant, $J /($ mole $\times K) ; \mathrm{T}$ - temperature, $\mathrm{K} ; M$ molecular weight, $\mathrm{kg} /$ mole.

- At the initial time:

$$
T_{1}(r, Z, 0)=T_{2}(r, Z, 0)=T_{0},
$$

where $T_{0}$ - temperature at $\mathrm{t}=0 \mathrm{~s}, \mathrm{~K}$.

- at the boundary $Z=0,0 \leq r \leq r_{2}$;

$$
T=T_{h} ;
$$

where $T_{h}$ - temperature of a geothermal source, $\mathrm{K}$.

- at the boundary $Z=H, 0 \leq r \leq r_{2}$;

$$
-\lambda_{1} \frac{\partial T_{1}}{\partial t}=\alpha\left(T_{c}-T_{e}\right) \text {, (4) }
$$

where $T_{c}$ - surface temperature, $\mathrm{K} ; T_{e}$ - ambient temperature, $\mathrm{K} ; \alpha$ - heat transfer coefficient, $W t /\left(m^{2} \cdot K\right)$.

- at the boundary $Z=H_{1}, 0 \leq r \leq r_{1}$;

$$
\left\{\begin{array}{l}
-\lambda_{1} \cdot \frac{\partial T_{1}}{\partial r}=-\lambda_{2} \cdot \frac{\partial T_{2}}{\partial r}-W_{e v} \\
T_{1}=T_{2}
\end{array}\right.
$$

- at the boundary $Z=H, 0 \leq r \leq r_{1}$;

$$
\left\{\begin{array}{l}
-\lambda_{1} \cdot \frac{\partial T_{1}}{\partial r}=-\lambda_{2} \cdot \frac{\partial T_{2}}{\partial r}+W_{c o} \\
T_{1}=T_{2} .
\end{array}\right.
$$

- at the boundary $r=0,0 \leq z \leq H+2 \cdot H_{1}$;

$$
\frac{\partial T}{\partial r}=0-\text { the symmetry condition. }
$$

- at the boundary $r=r_{2}, 0 \leq z \leq H+2 \cdot H_{1}$;

1) In the first series of mathematical modeling:

2) In the second series of mathematical modeling

$$
\begin{aligned}
& \frac{\partial T}{\partial r}=0 \\
& \text { deling } \\
& T=T_{p r}
\end{aligned}
$$

where $T_{p r}$ - ground temperature, $\mathrm{K}$.

at the boundary conditions of the fourth kind: 


$$
\left\{\begin{array}{l}
-\lambda_{1} \cdot \frac{\partial T_{1}}{\partial n}=-\lambda_{2} \cdot \frac{\partial T_{2}}{\partial n} ; \\
T_{1}=T_{2} .
\end{array}\right.
$$

The problem was solved by means of the finite difference method [10]. The convective term in the energy equation was discredited based on the locally one-dimensional Samarskogo`s scheme and monotonic A.A. Samarskogo`s approximations [11].In order to verify the mathematical model, algorithm used and solution method were tested on a model problem of heat transfer [11].

\section{Results and discussion}

The energy transfer investigation in a closed two-phase thermosyphon was carried out with the following parameters $T_{h}=373 \mathrm{~K}, \quad H=50 \mathrm{~m}, 10 \leq t \leq \infty \mathrm{s}, \alpha=23 \mathrm{Wt} /\left(\mathrm{m}^{2} \cdot K\right)$. The temperature closed two-phase thermosyphon fields in the output to the stationary mode of operation is shown in fig. 2.

Thus, the temperature of the top cover of the gas turbine at a running time of $10 \mathrm{~s}$ is the distance over which the pairs overcome $S=13 \mathrm{~m}$; for $t=50 \mathrm{~s}-T=316 \mathrm{~K}, S=28 \mathrm{~m}$; $t=100 \mathrm{~s}-T=324 \mathrm{~K}, S=35 \mathrm{~m} ; t=250 \mathrm{~s}-T=343 \mathrm{~K}, S=50 \mathrm{~m} ; t=\infty \mathrm{s}-T=360 \mathrm{~K}, \mathrm{~S}=50 \mathrm{~m}$; the upper cover temperature increases with the two-phase thermosyphon operating time. The temperature difference between the GTS top and bottom cover decreases from too due to an increase in the vaporization process intensity and the vapors velocity.

The temperature fields in the geothermal thermosyphon with a known temperature distribution in the soil are presented. In fig. 3. thus, the upper cover temperature of the gas turbine grows with increasing operating time from 312 to $315 \mathrm{~K}$ due to an additional heat exchange between the steam and the vertical walls. The temperature difference in the steam channel also decreases, as in the first experiments series.

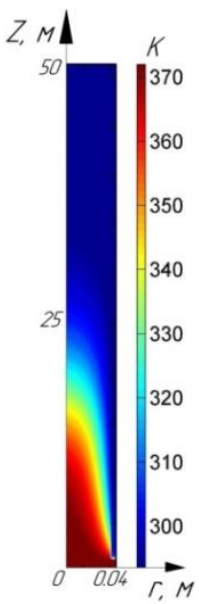

1)

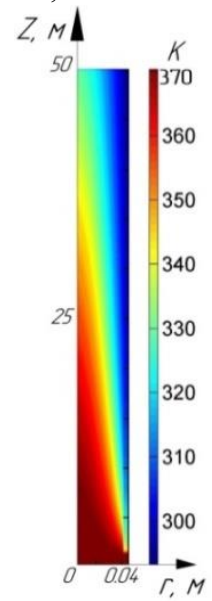

2)

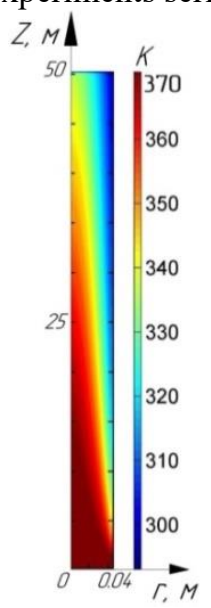

3)

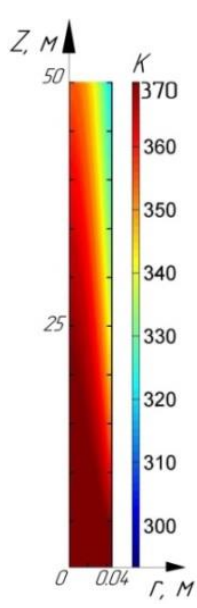

4)

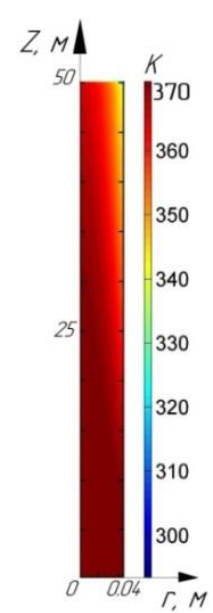

5)

Fig. 2. The steady state temperature fields for: 1) $t=10 s$; 2) $t=50 s$; 3) $t=100 s$; 4) $t=250 s ; 5$ ) $\mathrm{t}=\infty \mathrm{s}$.

According to the results of mathematical modeling, the main findings are as follows:

1. The mathematical model of heat and mass transfer in a closed two-phase thermosyphon with allowance for phase transformations of the refrigerant is formulated. 
2. The temperature difference between the top and bottom cover changes $293 \leq T \leq 360 K$, with increasing operating time $100 \leq t \leq \infty s$ of the geothermal thermosyphon.

3. The upper cover temperature also growths $313 \leq T \leq 315^{\circ} \mathrm{C}$ with increasing operating time taking into account the temperatures distribution in the ground and on the vertical wall of the gas turbine. The temperature is less than in the first approximation. The temperature difference varies within $50 \leq \Delta T \leq 60 K$.

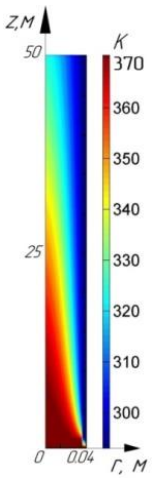

1)

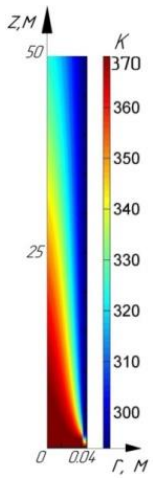

2)

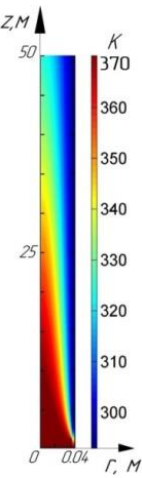

3)

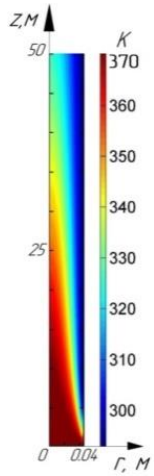

4)

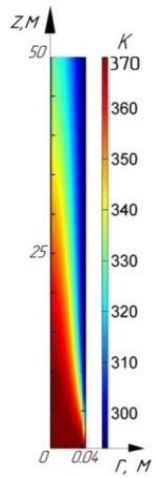

5)

Fig. 3. The steady state temperature fields for: 1) $t=100 s$; 2) $t=500 s$; 3) $t=1000 s$; 4) $t=5000 s ; 5) t=\infty$ s.

The reported research was supported by Russian Federation President Grant for state support of the Russian Federation leading scientific schools SS-7538.2016.

\section{References}

1. S. Yankovskiy, A. Matveev, A. Tolokolnikov, A. Zenkov, MATEC Web of Conferences, 92, 01036 (2016), DOI: 10.1051/matecconf/20179201036

2. S. Yankovsky, A. Tolokolnikov, A. Matveev, Y.Marysheva, MATEC Web of Conferences, 110, 01089 (2017), DOI: 10.1051/matecconf/201711001089

3. K.B. Larionov, I.V. Mishakov, A.A. Gromov, A.V. Zenkov, MATEC Web of Conferences, 91, 01007 (2017), DOI: 10.1051/matecconf/20179101007

4. A.V. Zenkov, K.B. Larionov, V.Gubin, MATEC Web of Conferences, 110, 01091 (2017), DOI: $10.1051 /$ matecconf/201711001091

5. S. Carlino, R. Somma, A. Troiano, M.G. Di Giuseppe, C. Troise, G. De Natale, J. Ren. En., 62, 177-196 (2014), DOI: 10.1016/j.renene.2013.06.052

6. A. Franco, M. Vaccaro, J. Appl. Th. Eng., 59, 189-199 (2013), DOI: 10.1016/j.applthermaleng.2013.05.024

7. A. Hantsch, U. Gross, J. Geoth., 47, 97-103 (2013), DOI: 10.1016/j.geothermics.2013.03.003

8. F. Hartmann, R. Behrend, A. Hantsch, T. Grab, U. Gross, J. Geoth., 55, 99-107 (2015), DOI: $10.1016 /$ j.geothermics.2015.01.014

9. G. V. Kuznetsov, M. A. Sheremet, Therm. and Aerom., 16, 123-133 (2009), DOI: 10.1007/s11510-009-0012-z

10. V.M. Paskonov, V.I. Polezhaev, and L.A. Chudov, Numerical Modeling of heat and mass Exchange Processes (Nauka, Moscow, 1984)

11. Saedi S.M., Khodadadi J.M., J. Heat and Mass Transf., 49, 1896-1906 (2006), DOI: 10.1016/j.ijheatmasstransfer.2005.10.033 